\title{
A model for optimizing electronic toll collection systems
}

\author{
David Levinson *, Elva Chang \\ Department of Civil Engineering, University of Minnesota, 500 Pillsbury Drive SE, Minneapolis, MN 55455, USA
}

Received 6 September 1999; received in revised form 12 February 2002; accepted 19 February 2002

\begin{abstract}
This paper examines the deployment of electronic toll collection (ETC) and develops a model to maximize social welfare associated with a toll plaza. A payment choice model estimates the share of traffic using ETC as a function of delay, price, and a fixed cost of acquiring the in-vehicle transponder. Delay in turn depends on the relative number of ETC and manual collection lanes. Price depends on the discount given to users of the ETC lanes. The fixed cost of acquiring the transponder (not simply a monetary cost, but also the effort involved in signing up for the program) is a key factor in the model. Once a traveler acquires the transponder, the cost of choosing ETC in the future declines significantly. Welfare depends on the market share of ETC, and includes delay and gasoline consumption, toll collection costs, and social costs such as air pollution. This work examines the best combination of ETC lanes and toll discount to maximize welfare. Too many ETC lanes cause excessive delay to non-equipped users. Too high a discount costs the highway agency revenue needed to operate the facility. The model is applied to California's Carquinez Bridge, and recommendations are made concerning the number of dedicated ETC lanes and the appropriate ETC discount.
\end{abstract}

(C) 2003 Elsevier Science Ltd. All rights reserved.

\section{Introduction}

Newly deployed electronic toll collection (ETC) systems enable bridge, tunnel, and turnpike operators to reduce both staff and delay. Such systems are not deployed instantaneously. Agencies need to familiarize themselves with the technology, while distrust and procrastination cause many users to defer expending time or resources to acquire transponders and establish accounts. To speed adoption of ETC, some fraction of the cost savings could be returned as a discount for ETC users to optimize the use of the lanes, leaving everyone better off. The Golden Gate Bridge in

\footnotetext{
* Corresponding author. Tel.: +1-612-625-6354.

E-mail address: levin031@tc.umn.edu (D. Levinson).
} 
California chose this strategy initially (Fimrite, 2001). Alternatively, monetary cost of acquiring a transponder could be reduced. For instance, the Japanese Transport Ministry announced a $20 \%$ discount on in-vehicle equipment (which had cost 50,000 yen plus 7000 yen installation), since only 12,000 devices had been sold despite the availability of ETC at 63 tollbooths (Asahi Shimbun, 2001). Moreover, in the absence of automatic vehicle identification, people without transponders must be accommodated by manual lanes.

The intent of this paper is to inform decisions that tolling agencies must make regarding toll discounts, transponder availability and ETC lane dedication. This paper therefore tackles the question of how quickly lanes should be converted to ETC and what discount for using ETC would be socially optimal, and extends previous research on ETC (Al-Deek et al., 1996; Al-Deek et al., 1997; Burris and Hildebrand, 1996; Friedman and Waldfogel, 1995; Hensher, 1991; Lin and Su, 1994; Robinson and Van Aerde, 1995; Sisson, 1995; Woo and Hoel, 1991; Zarrillo et al., 1997).

However asking such questions is much easier than answering them. Ideally the models developed must dynamically optimize over a flexible choice set. For instance, one would like to determine what share of the initial reluctance to switch to electronic tolls is fixed with the individual, based on measurable socio-economic, demographic, and geographic factors, what share depends on exposure, and what share is simply random. An agency's decision to deploy ETC lanes in one year shapes the market it faces in the next.

This paper first discusses a dynamic payment choice model that predicts the users' choice between manual and electronic tolls. Societal benefits and costs and user payment choices, which vary with demand and the number of ETC lanes, are needed to determine the best combination in the optimization exercise. The welfare maximization model is applied to the Carquinez Bridge case. A series of sensitivity analyses, varying the key model parameters, are performed. Finally, some conclusions are drawn about the pace of deploying electronic toll collection.

\section{Dynamic payment choice model}

The dynamic payment choice model explains the share of manual and electronic payment. In this model, travel time, lane configuration, toll discount, and payment choice are all interdependent. This model considers the decisions of drivers (who must choose whether to equip their vehicle with ETC) during peak periods, including both regular and occasional users (though passenger value of time is considered in the benefits calculation). Details on the benefit-cost analysis and assumptions are given in Appendix A.

\section{Payment choice}

It is hypothesized that the choice between manual or electronic payment by drivers depends on the out-of-pocket cost and the time associated with each alternative. The choice also depends on a one-time fixed cost associated with electronic toll collection, frequency of use of the facility, convenience associated with avoiding cash or tickets, and the ease with which the toll agency makes transponders available. Because there is no data available for these other factors, they are 
embedded in an ETC-specific constant. This constant is expected to have a negative sign since travelers must obtain transponders and open an ETC account. Sensitivity tests examine alternative constants. The logit functional form was chosen for its simplicity of application rather than because of its error distribution (Train, 1986). The linear utility function implies substitutability between the travel time and out-of-pocket costs. The model posits that individuals using manual payment re-evaluate their payment mechanism each time there is a change in circumstances (in this case traffic growth, a change in the configuration of lanes, and/or discount policy), assumed to be once per year. More frequent user re-evaluation would entail a change in the model because of the irreversibility assumption described below.

This model estimates payment choice among those who are presently users of manual lanes. In this model, there is an irreversibility assumption, that an individual who has chosen ETC stays with electronic payment. However, a certain fraction of electronic payment users are lost each year because of changing commute patterns associated with retirement, moving or changing jobs. The fraction of those who stay with the same commute from year to year is dubbed the "survival rate" $(R)$. Previous research evaluating the survival of commutes between the same home and workplace gives a value of $84 \%$ (Levinson, 1997). The shares for surviving commutes are shown in Eq. (1a). It is assumed that all replacement for non-survivors (new commuters due to relocation) are manual travelers (as shown in Eq. 1b). The model thus misses the share of relocating commuters who possess a compatible transponder, creating a small bias. Traffic growth is exogenous, and not part of the share calculations. All new traffic faces the market share determined in Eq. (1c). This also creates a small bias, as traffic growth (assumed 3\% per year-see Appendix A) is distributed the same way as previous and replacement traffic, rather than as manual traffic. These biases are in offsetting directions.

The model for existing commuters is given by:

$$
\begin{aligned}
& S_{\mathrm{e}, n, \mathrm{x}}=R\left(S_{\mathrm{e}, n-1}+\left(S_{\mathrm{m}, n-1}\right) \frac{\mathrm{e}^{U_{\mathrm{e}, n}}}{\mathrm{e}^{U_{\mathrm{e}, n}}+\mathrm{e}^{U_{\mathrm{m}, n}}}\right) \\
& S_{\mathrm{m}, n, \mathrm{x}}=R\left(\left(S_{\mathrm{m}, n-1}\right) \frac{\mathrm{e}^{U_{\mathrm{m}, n}}}{\mathrm{e}^{U_{\mathrm{e}, n}}+\mathrm{e}^{U_{\mathrm{m}, n}}}\right)
\end{aligned}
$$

The model for replacement commuters is given by:

$$
\begin{aligned}
& S_{\mathrm{e}, n, \mathrm{w}}=(1-R) \frac{\mathrm{e}^{U_{\mathrm{e}, n}}}{\mathrm{e}^{U_{\mathrm{e}, n}}+\mathrm{e}^{U_{\mathrm{m}, n}}} \\
& S_{\mathrm{m}, n, \mathrm{w}}=(1-R) \frac{\mathrm{e}^{U_{\mathrm{m}, n}}}{\mathrm{e}^{U_{\mathrm{e}, n}}+\mathrm{e}^{U_{\mathrm{m}, n}}}
\end{aligned}
$$

such that:

$$
S_{\mathrm{e}, n, \mathrm{w}}+S_{\mathrm{m}, n, \mathrm{w}}+S_{\mathrm{e}, n, \mathrm{x}}+S_{\mathrm{m}, n, \mathrm{x}}=1
$$

The market shares for new commuters (traffic growth) are implicitly assumed to be:

$$
\begin{aligned}
& S_{\mathrm{e}, n, \mathrm{v}}=S_{\mathrm{e}, n, \mathrm{w}}+S_{\mathrm{e}, n, \mathrm{x}} \\
& S_{\mathrm{m}, n, \mathrm{v}}=S_{\mathrm{m}, n, \mathrm{w}}+S_{\mathrm{m}, n, \mathrm{x}}
\end{aligned}
$$

such that:

$$
S_{\mathrm{e}, n, \mathrm{v}}+S_{\mathrm{m}, n, \mathrm{v}}=1
$$


where $R$ is survival rate of commutes; $S_{\mathrm{e}, n, \mathrm{x}}, S_{\mathrm{m}, n, \mathrm{x}}$ are share of existing ETC, manual users in year $n ; S_{\mathrm{e}, n, \mathrm{w}}, S_{\mathrm{m}, n, \mathrm{w}}$ are share of replacement ETC, manual users in year $n ; S_{\mathrm{e}, n, \mathrm{v}}, S_{\mathrm{m}, n, \mathrm{v}}$ are share of new ETC, manual users in year $n ; U_{\mathrm{e}, n}$ is utility of electronic tolls in year $n=\alpha_{0}+\alpha_{1} T_{\mathrm{e}}+\alpha_{2} P_{\mathrm{e}} ; U_{\mathrm{m}, n}$ is utility of manual tolls in year $n=\alpha_{1} T_{\mathrm{m}}+\alpha_{2} P_{\mathrm{m}} ; T_{\mathrm{e}}, T_{\mathrm{m}}$ are travel time in ETC, manual lane (min); $P_{\mathrm{e}}, P_{\mathrm{m}}$ are toll in ETC, manual lane (\$/vehicle); $\alpha_{1}, \alpha_{2}, \alpha_{3}$ are model parameters.

In year 1 , the share of ETC users in the previous year is 0 , so the probability of choosing a payment depends only on its relative utility in that year. As time passes people moving to the area are increasingly likely to have transponders which they bring from other areas (e.g. in the Carquinez Bridge case, compatible transponders from elsewhere in California). This percentage is unknown, but suggests actual adoption might be somewhat higher than this model would indicate. The probability of a new bridge user choosing electronic tolls in a given year depends on the utility that the user faces in that year, which may differ from what users faced in previous (or will face in future) years. The model is solved for a representative traveler at the expected value of delay and the given discount and ETC-specific constant.

The baseline scenario coefficient on time was borrowed from previous studies on the sensitivity of choice to travel time $\left(\alpha_{1}=-0.03\right)$ (Ben-Akiva and Lerman, 1985). The logit scale parameter $\alpha_{\mathrm{GEV}}$ is assumed to equal 1 (Train, 1986). From this and the assumed weighted value of time $\left(V_{\mathrm{T}}\right)$ of $\$ 17.41$ per vehicle-hour (Gillen et al., 1999), the coefficient on price is estimated. Using baseyear data and these values, an alternative-specific constant $\left(\alpha_{0}\right)$ is computed. Model predictions are compared to actual, year 2 experience. To test the model, a sensitivity analysis of various parameters was conducted; this is discussed in a later section. The coefficient on price $\left(\alpha_{2}\right)$ was computed with the following expression:

$$
\alpha_{2}=\frac{60 \alpha_{1}}{V_{\mathrm{T}}}=-0.1034
$$

However, this value of time is just a broad system average, so sensitivity analyses are performed later with different values (and consequently different values for the model coefficients). In the first year (FY97/98), the share of travelers using electronic toll collection $\left(S_{\mathrm{e}}\right)$ was $6 \%$. Using base-year traffic data a time difference between an average ETC user and manual user $\left(T_{\mathrm{e}}-T_{\mathrm{m}}\right)$ of $-35 \mathrm{~s}$ is estimated. Moreover, a discount of \$0.15/trip was introduced to ETC users in the first year. The $\alpha_{0}$ was solved that would result in the model returning the first year values for share of ETC users $\left(S_{\mathrm{e}, 1}\right)$ with the following expression:

$$
\alpha_{0}=\ln \left(\frac{S_{\mathrm{e}, 1}}{1-S_{\mathrm{e}, 1}}\right)-\alpha_{1}\left(T_{\mathrm{e}}-T_{\mathrm{m}}\right)-\alpha_{2}\left(P_{\mathrm{e}}-P_{\mathrm{m}}\right)=-3.08
$$

Notice that the size of the ETC-specific coefficient exceeds the other parameters. It means that a significant amount of savings in time and money is needed to overcome the hurdle to adopt ETC technology. When the savings are moderate, travelers would rather endure a slightly longer travel time than go through the process of obtaining a transponder. However, when the savings are significant, or ETC is required to obtain travel time savings as on SR 91 in Orange County, California, or the benefits are spread over multiple facilities (many toll facilities use the technology), experience has shown that commuters will be more likely to use the new technology. To illustrate, the Fastrak compatible Orange County's Transportation Corridor Agencies routes have 
daily ETC use in excess of 50\% and peak use in excess of $80 \%$ (ETTM, 2001), while the compatible ETC system on the Golden Gate Bridge has over 40\% market share (Fimrite, 2001).

\section{ETC disposition and network externalities}

The constant $\left(\alpha_{0}\right)$ can be interpreted as a fixed cost associated with obtaining transponders, implicitly a predisposition against switching from manual to ETC. However, this disposition may change over time. There are several parallel but offsetting processes.

In year 1, some drivers adopt ETC. These early adopters must have a smaller than average predisposition against the technology; that is their constant $\left(\alpha_{0}^{\text {adopt }}\right)$ is less negative. Hence, those who do not adopt in the first year must have a more negative value of the constant $\left(\alpha_{0}^{\text {notadopt }}\right)$. In year 2 , the average predisposition against adoption rises even more among those who have not adopted (all other things equal). However, it is impossible to know from the available data how much higher the predisposition is, because there are many unknown factors affecting payment choice in addition to variations in the constant $\left(\alpha_{0}\right)$.

The willingness to try ETC may increase with the rate of adoption if network externalities exist. These include multiple uses of transponders, including toll plazas, parking garages, drive-through windows for fast food and gas at service stations. Additional uses become increasingly viable the more existing uses and users, and make acquiring a transponder that much more valuable. In addition, the longer a system has been deployed, the more confidence potential users have in the system. In general, as knowledge of a technology and realization of its benefits spreads, the rate of adoption increases because each project acts as a demonstration to potential new users.

The net effect of these offsetting factors is unclear, so sensitivity tests will be performed. First, as a default (baseline) assumption, $\left(\alpha_{0}\right)$ will simply be reduced from its base-year value to 0 in year 20 linearly. Second, for sensitivity analyses, $\left(\alpha_{0}\right)$ will be multiplied by the share of manual users $\left(S_{\mathrm{m}}\right)^{z}$ (where the power term $z$ is sensitivity variable) to see what happens to willingness to adopt as the background share of manual users decreases from 100\% in the base. This models the combined effect of the network externality and individual predisposition.

\section{Policy variables: capacity and discount}

According to the choice model, the toll agency can affect the evolution of ETC share in several ways: providing a discount exclusively for ETC users; imposing congestion in the manual lanes by supplying more ETC capacity than needed (and reducing the capacity of manual lanes); and reducing the buy-in hurdle, the fixed cost associated with ETC. In the basic model, the toll agency decides the discount and the number of ETC lanes every year corresponding to the forecast ETC share that maximizes the overall social welfare (the sum of benefits to the agency, commuters, and the community, minus their costs, defined more precisely in Appendix A), such that ETC delay is less than manual delay. However, this is myopic. By adding more ETC lanes and closing manual lanes, travelers will switch to ETC payment and ETC market share will grow. This may result in greater benefits in the end, despite deviating from the short-run optimal. This issue would be eliminated if the model could solve the optimization problem simultaneously over 20 years rather 
than sequentially year by year. Unfortunately, an exact, non-heuristic, solution for the multi-year optimization is not possible at this time due to the size of the problem, though some less myopic strategies in the sensitivity analysis are examined below. Lanes are either manual or ETC (shared ETC and manual lanes are assumed to be manual) ${ }^{1}$. To illustrate the size of the problem, for one year the agency must choose between 1 and 11 lanes (along with discounts). To optimize for two years, one has to choose over $11^{2}$ lanes (the number of lanes in each year), so for 20 years in principle, there are $11^{20}$ possible choices to optimize simultaneously (rather than $11 \times 20$ in the myopic optimization). While some simplifying assumptions such as irreversibility may be made; it is a large problem to solve. It should be noted that the model is insensitive to the engineering question of lane-location of ETC vs. manual lanes (i.e. should the ETC lanes be leftmost, rightmost, or in the center, or should they be together or separated), which is an important question that would affect weaving at toll plazas. While safety might be enhanced by allowing ETC in all lanes, time savings are improved only if there are exclusive, non-stop ETC lanes.

Given the number of ETC lanes, annual traffic volume, and the dynamic payment model, there is an optimal discount that maximizes the overall social welfare in any given year. For each year 2 through 20, an optimal combination of ETC lanes and discount is chosen to maximize the overall social welfare so long as the net benefit of the toll agency is non-negative. This constraint is set to encourage the toll agency to implement the ETC system, and may result in discontinuities in the optimization. Different buy-in hurdles are tested in the sensitivity analysis.

\section{Model system}

Given the number of ETC lanes, discount policy and annual traffic volume, the ETC market share is estimated from the payment choice model. Then, the costs incurred and benefits gained for each class are calculated. An iterative algorithm searches for the optimal combination of ETC lane configuration (and thus delay) and discount policy to maximize total social welfare given the market demand function.

Fig. 1 shows a flowchart that illustrates the model system. The base-year configuration of the toll plaza, survival rate, payment choice parameters, and optimal discount are initialized. The equilibrium market share is found by a grid search, establishing a market share that would return traffic delays that result in the same market share, given a discount and lane configuration. If the net present value from that configuration is better than all previous net present values (NPVs) for that year, the lane configuration and discount are stored as optimal; otherwise, the previous optimal combination is retained. As long as the discount is not at a maximum, it is incremented. If the number of lanes for ETC is not at a maximum, the ETC lanes are incremented. At the end of a year's trials, the information for that year is stored, the optimal configuration selected, and the

\footnotetext{
${ }^{1}$ On the Carquinez Bridge toll plaza, two lanes were opened for mixed ETC/manual toll collection. Since vehicles equipped with ETC suffer delay when the driver of the leading vehicle pays the toll manually in mixed use lanes, the gains from mixed payment lanes are expected to be marginal and are thus neglected in the model. Mixed lanes are treated as manual lanes in this exercise and it is assumed that all vehicles equipped with transponders only use the ETCdedicated lane.
} 


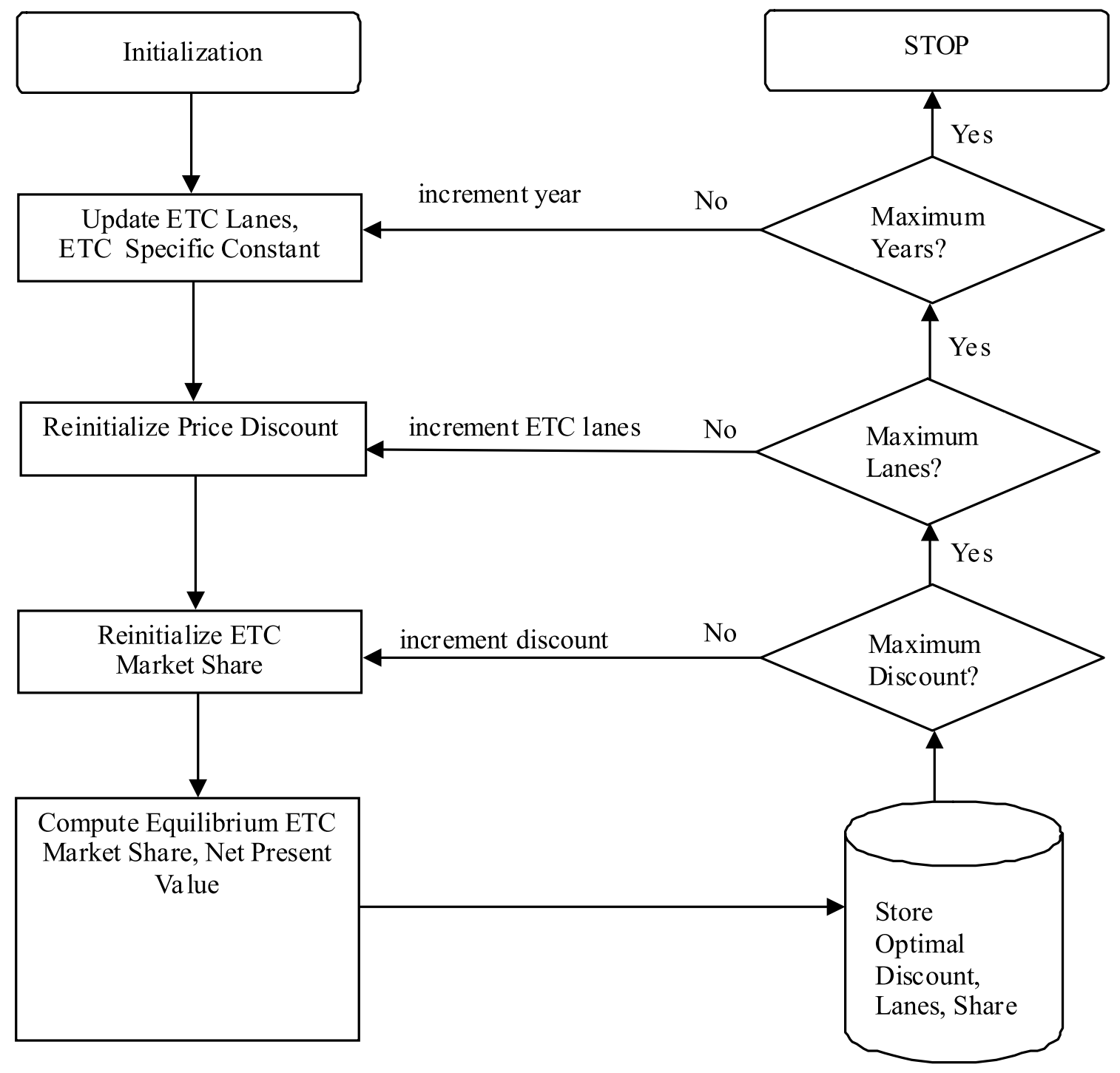

Fig. 1. Flowchart of the basic ETC optimization model.

model is run for the next year, through year 20. The software for solving this is documented in Chang et al. (1998).

\section{Results}

Data from the Carquinez Bridge in northern California are used to illustrate the procedure to determine an appropriate pace of ETC deployment and discount policy. The Carquinez Bridge was selected as the ETC pilot implementation in the San Francisco Bay Area because it has 
sufficient capacity to accommodate current traffic (Gillen et al., 1999). The toll plaza contains 12 lanes. Since August 21, 1997, a dedicated ETC lane has been opened to travelers with transponders.

The optimal discount policy and pace of ETC deployment under specific assumptions made in this study are shown on Table 1 (the rest of the table shows sensitivity analyses discussed in the next section). The overall net present value is about 74 million dollars. The benefit-cost ratio (the sum of the agency's benefits in terms of cost savings divided by their expenditures for the new technology) for the toll agency is much less than 1 , it is 0.24 , indicating that the agency does not have any reason to proceed with the project if it chooses to ignore community welfare. However, for society overall, benefits greatly exceed costs (benefit-cost ratio of 28.43, internal rate of return of $51.5 \%$, primarily because of delay reductions. Table 2 presents detailed results for this scenario, showing how the overall NPV, ETC share, discounts, and number of lanes vary by year.

Table 1

Summary of results

\begin{tabular}{|c|c|c|c|c|c|c|}
\hline & Overall NPV & Agency & Users & Society & $\begin{array}{l}\text { Maximum } \\
\text { lanes }\end{array}$ & $\begin{array}{l}\text { Saturation ETC } \\
\text { share }(\%)\end{array}$ \\
\hline \multicolumn{7}{|l|}{ Baseline } \\
\hline & $\$ 73,835,899$ & $-\$ 1,586,679$ & $\$ 75,360,179$ & $\$ 62,400$ & 8 & 86.82 \\
\hline \multicolumn{7}{|c|}{ Survival rate } \\
\hline $95 \%$ & $\$ 81,832,093$ & $-\$ 1,417,912$ & $\$ 83,180,926$ & $\$ 69,080$ & 10 & 95.47 \\
\hline $75 \%$ & $\$ 68,311,591$ & $-\$ 1,708,067$ & $\$ 69,961,850$ & $\$ 57,808$ & 7 & 80.84 \\
\hline $60 \%$ & $\$ 60,715,884$ & $-\$ 1,550,326$ & $\$ 62,214,736$ & $\$ 51,474$ & 6 & 72.53 \\
\hline $40 \%$ & $\$ 52,878,116$ & $-\$ 1,615,916$ & $\$ 54,449,127$ & $\$ 44,905$ & 5 & 63.87 \\
\hline $20 \%$ & $\$ 46,540,082$ & $-\$ 1,785,871$ & $\$ 48,286,206$ & $\$ 39,747$ & 4 & 57.13 \\
\hline \multicolumn{7}{|c|}{ Value of time } \\
\hline$\$ 174$ & $\$ 401,875,521$ & $\$ 3,098,232$ & $\$ 398,705,738$ & $\$ 71,551$ & 11 & 94.51 \\
\hline$\$ 1.74$ & $\$ 43,993,659$ & $-\$ 1,300,174$ & $\$ 45,231,678$ & $\$ 62,155$ & 9 & 86.64 \\
\hline \multicolumn{7}{|l|}{ Power term } \\
\hline 2 & $\$ 75,503,504$ & $-\$ 1,494,009$ & $\$ 76,933,426$ & $\$ 64,087$ & 8 & 86.20 \\
\hline 1 & $\$ 53,754,348$ & $-\$ 1,573,507$ & $\$ 55,282,089$ & $\$ 45,766$ & 6 & 74.67 \\
\hline 0.5 & $\$ 24,514,291$ & $\$ 1,042,714$ & $\$ 23,445,267$ & $\$ 26,310$ & 3 & 46.35 \\
\hline 0.33 & $\$ 10,460,399$ & $-\$ 1,819,623$ & $\$ 12,261,059$ & $\$ 18,963$ & 3 & 39.64 \\
\hline 0.25 & $\$ 6,299,887$ & $-\$ 1,871,985$ & $\$ 8,155,251$ & $\$ 16,620$ & 3 & 38.47 \\
\hline 0.125 & $-\$ 771,101$ & $-\$ 1,838,256$ & $\$ 1,054,487$ & $\$ 12,668$ & 2 & 34.76 \\
\hline 0 & $-\$ 9,090,115$ & $-\$ 1,897,567$ & $-\$ 7,200,851$ & $\$ 8302$ & 2 & 33.45 \\
\hline-1 & $-\$ 32,403,453$ & $\$ 1,825,355$ & $-\$ 34,223,128$ & $-\$ 5680$ & 1 & 19.49 \\
\hline \multicolumn{7}{|c|}{ Capacity rules } \\
\hline+1 year 1 & $\$ 68,311,591$ & $-\$ 1,708,067$ & $\$ 69,961,850$ & $\$ 57,808$ & 7 & 80.84 \\
\hline+1 year 2 & $\$ 52,878,116$ & $-\$ 1,615,916$ & $\$ 54,449,127$ & $\$ 44,905$ & 5 & 63.87 \\
\hline+2 year 1 & $\$ 60,715,884$ & $-\$ 1,550,326$ & $\$ 62,214,736$ & $\$ 51,474$ & 6 & 72.53 \\
\hline+2 year 2 & $\$ 46,540,082$ & $-\$ 1,785,871$ & $\$ 48,286,206$ & $\$ 39,747$ & 4 & 57.13 \\
\hline \multicolumn{7}{|c|}{ Optimization bundling } \\
\hline Two-year & $\$ 95,084,413$ & $-\$ 4,815,726$ & $\$ 99,816,884$ & $\$ 83,254$ & 10 & 88.43 \\
\hline Three-year & $\$ 83,386,893$ & $-\$ 4,563,586$ & $\$ 87,871,877$ & $\$ 78,602$ & 11 & 92.63 \\
\hline
\end{tabular}


Table 2

Detailed results for baseline scenario

\begin{tabular}{llllll}
\hline Year & ETC share $(\%)$ & Overall NPV & Discount & $\begin{array}{l}\text { Time difference } \\
(\mathrm{min})\end{array}$ & ETC lanes \\
\hline 0 & 0.00 & $-\$ 2,223,592$ & & & \\
1 & 5.98 & $\$ 253,415$ & $-\$ 0.11$ & -0.59 & 1 \\
2 & 11.54 & $\$ 531,627$ & $-\$ 0.13$ & -0.56 & 1 \\
3 & 17.69 & $\$ 854,635$ & $-\$ 0.14$ & -0.50 & 2 \\
4 & 25.41 & $\$ 1,215,254$ & $-\$ 0.14$ & -0.57 & 2 \\
5 & 35.25 & $\$ 1,737,885$ & $-\$ 0.15$ & -0.53 & 3 \\
6 & 46.89 & $\$ 2,326,685$ & $-\$ 0.16$ & -0.55 & 5 \\
7 & 58.74 & $\$ 3,044,073$ & $-\$ 0.17$ & -0.55 & 5 \\
8 & 68.92 & $\$ 3,751,064$ & $-\$ 0.20$ & -0.56 & 6 \\
9 & 76.32 & $\$ 4,348,375$ & $-\$ 0.22$ & -0.54 & 7 \\
10 & 81.06 & $\$ 4,747,283$ & $-\$ 0.24$ & -0.55 & 7 \\
11 & 83.81 & $\$ 5,034,428$ & $-\$ 0.25$ & -0.55 & 7 \\
12 & 85.30 & $\$ 5,181,423$ & $-\$ 0.27$ & -0.56 & 8 \\
13 & 86.07 & $\$ 5,292,668$ & $-\$ 0.28$ & -0.56 & 8 \\
14 & 86.45 & $\$ 5,334,956$ & $-\$ 0.29$ & -0.56 & 8 \\
15 & 86.63 & $\$ 5,357,705$ & $-\$ 0.30$ & -0.58 & 8 \\
16 & 86.72 & $\$ 5,396,055$ & $-\$ 0.31$ & -0.58 & 8 \\
17 & 86.76 & $\$ 5,403,914$ & $-\$ 0.32$ & -0.58 & \\
18 & 86.79 & $\$ 5,410,090$ & $-\$ 0.33$ & -0.58 & \\
19 & 86.81 & $\$ 5,415,931$ & $-\$ 0.34$ & -0.58 & \\
20 & 86.82 & $\$ 5,422,026$ & $-\$ 0.35$ & -0.59 & \\
Total & & $\$ 73,835,899$ & & & \\
\hline
\end{tabular}

Fig. 2 depicts the evolution of ETC share over the 20-year period of analysis for a number of scenarios regarding survival rate, with the $84 \%$ survival rate taken as the baseline. In year 20 , the model projects that ETC market share will reach $87 \%$ and there will be eight ETC lanes for the baseline scenario.

\section{Sensitivity analyses}

Several sensitivity analyses are performed in this study. They are shown in Table 1 and Figs. 2-7. The survival rate, value of time, ETC specific constant, and capacity rules are varied in turn.

\subsection{Survival rate}

In the original model, the survival rate is taken as $84 \%$. The higher the survival rate, the more people who have chosen ETC payment will continue to use the system in the coming year. Hence, it is suspected that a higher ETC share would be reached in year 20 as the survival rate increases. The evolution of ETC market share under different survival rates is shown on Fig. 2 (constrained so the annual NPV of the toll agency is greater than 0).

As the survival rate falls, the operator has to provide greater incentives (via time and money differentials) to achieve the same level of market share. An interesting (and unexpected) behavior 


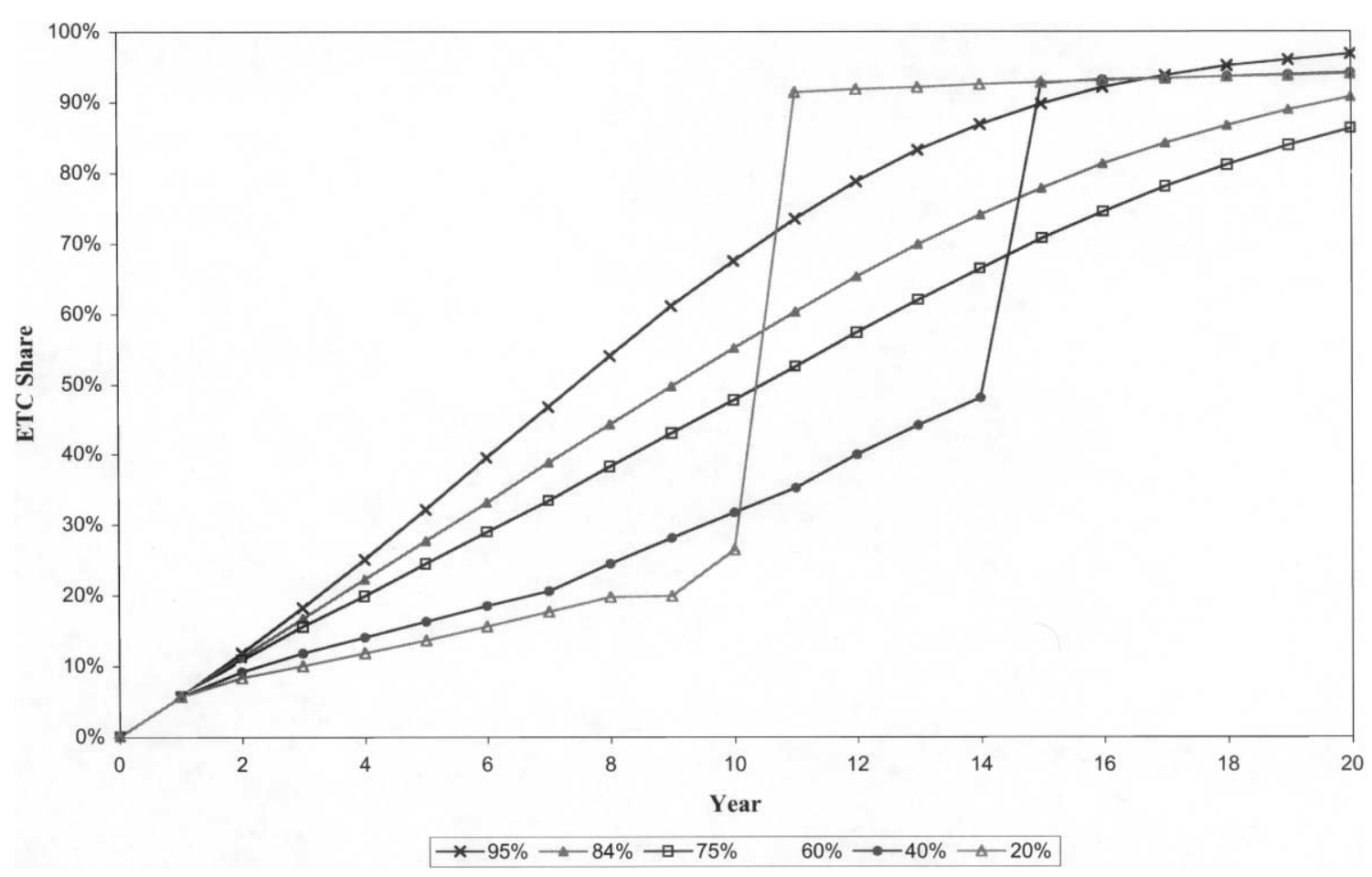

Fig. 2. Evolution of ETC market share under different survival rate.

emerges for survival rates below $40 \%$. The interplay of the overall welfare optimization and two constraints (the operator has non-negative revenue and the ETC lanes are always faster than the manual lanes) leads to what one might consider a complex phase change. It seems that the toll agency chooses to allocate more ETC lanes (11 in total) to enlarge the travel time difference between the two payment choices, and this strategy brings about a higher market share in year 20 and a somewhat higher overall NPV. This strategy of using the maximum number of ETC lanes does not maximize welfare for higher survival rate cases. The comparison of NPV across different survival rates is shown on Table 1, clearly the higher the survival rate, the higher the overall market share and thus NPV.

\section{Value of time}

In the original model, the value of time is taken as $\$ 17.41 / \mathrm{h} /$ vehicle. Two alternative values of time also are tested, these are 10 times greater than and 10 times less than the original value. While these may seem extreme, these numbers bound all reasonable values of time. Furthermore, two other points are worth noting. First in the absence of real time savings (i.e. in the absence of congestion), travel time hardly affects the choice. Second, value of time affects the utility of both manual and electronic payment. When travelers have a higher value of time, they are more sensitive to the potential time saved by switching to ETC payment. It is expected that travelers would adopt the ETC system earlier, and the final ETC market share is going to be higher, the greater the value of time. The results shown on Fig. 3 confirm the reasoning. 


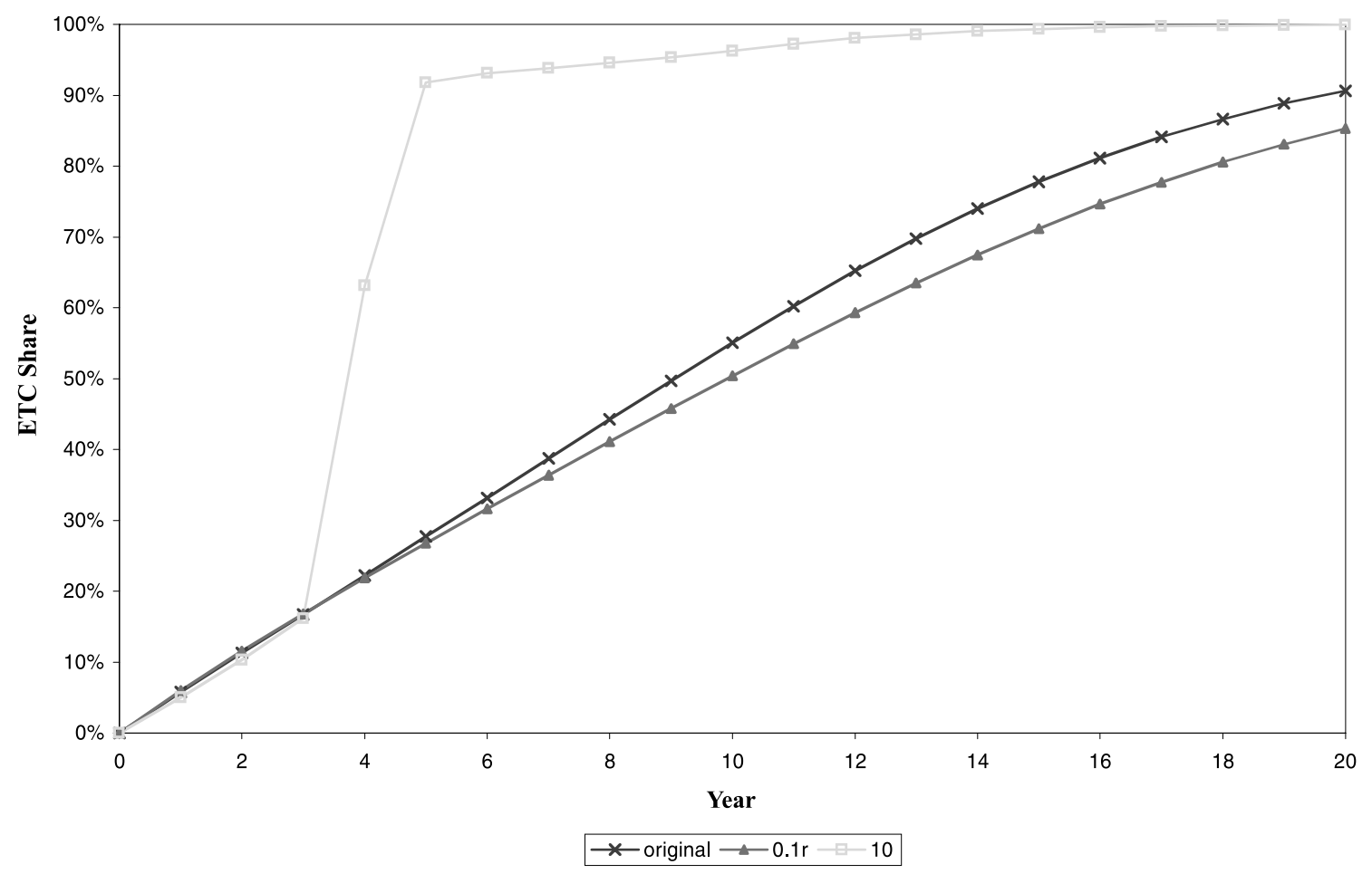

Fig. 3. Evolution of ETC market share under different value of time.

The market share under a high value of time exceeds that with lower values as shown on Table 1. Although a radically lower value of time does not harm greatly the pace of ETC adoption, the overall social welfare increases dramatically with the higher value of time. As in the original model, travelers accrue the majority of benefits (original model 102\%, low value of time $103 \%$, high value of time 99\%). Notice that the toll agency also recovers its initial capital investment with a higher value of time. The early realization of high ETC market share entitles the toll agency to enjoy significant cost reductions, primarily toll collection staff, for a longer period.

Highly non-linear models of the logit form can yield biased results when applied to average input values of independent variables. Sample enumeration can deal with the actual distribution of commuters' values of time (Miller, 1996; Ortuzar and Willumsen, 1996; Purvis, 1996). In principle, sample enumeration is preferred, however there are several practical issues. The first is knowing the distribution of a representative sample. In this case, the underlying distribution is unknown, all that is available is an estimate of the average value of time for the population. While one could assume a distribution, that would introduce a different set of errors. Second, this is a long-run analysis, so even if the distribution were known, there is no assurance it would remain constant over time. Third is the practical effect that such a change would produce. Experiments of doing a sample enumeration approach on value of time show very little change. To test sample enumeration, the value of time is varied between $\$ 1 / \mathrm{h}$ and $\$ 34 / \mathrm{h}$ (straddling the assumed average $(\$ 17.41 / \mathrm{h})$, shown in Fig. 4 (assuming base year, relatively uncongested conditions). A uniform distribution of values of time between these two values (an extreme case, as a real sample is likely to 


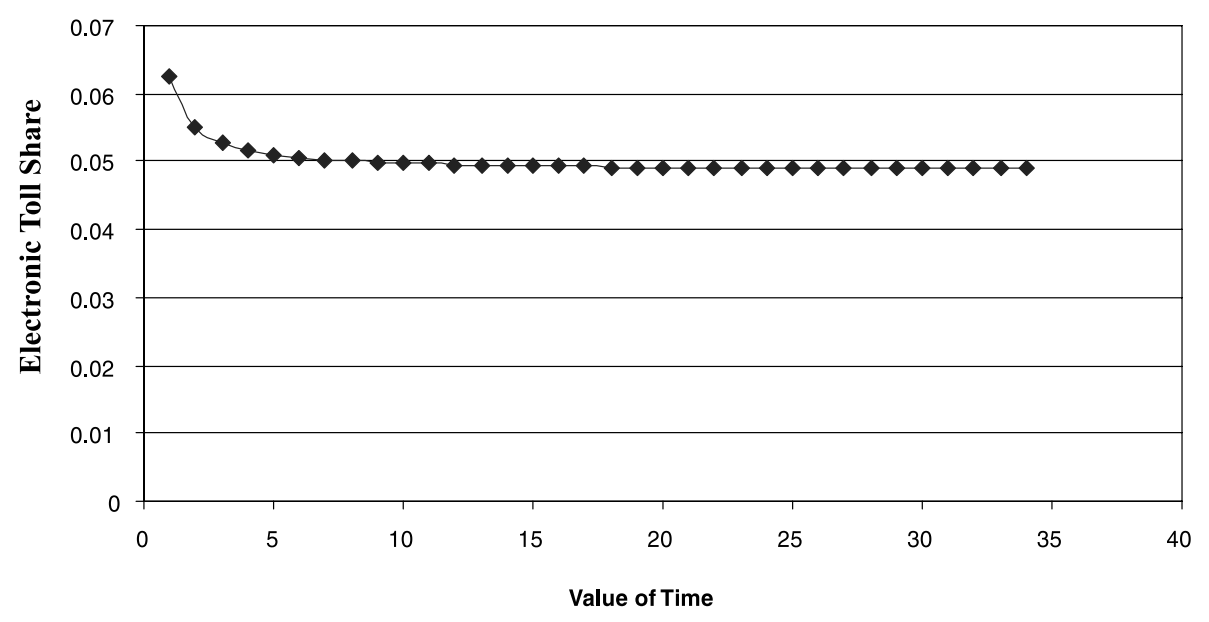

Fig. 4. Share of electronic tolls vs. value of time.

cluster about the mean) results in a mean share of electronic tolls of 0.0502 , rather than 0.0493 which obtained from simply using the average value of time in the first place. A normal distribution would be even closer to the original mean. As a result, it is concluded that over the range of values of the variables in this paper, this simplification is unlikely to significantly bias the final results.

\section{ETC specific constant and network externalities}

The reluctance to switch to ETC may decrease over time, but it is unclear how quickly. In the original model it is posited that the ETC-specific constant $\left(\alpha_{0}\right)$ in the logit choice model hits zero in year 20 by decreasing at a uniform rate. In this section, different rates are investigated. Following the argument about network externalities, the magnitude of this constant is associated with the share of ETC users (or non-users). Here $\alpha_{0}=\alpha_{0} S_{\mathrm{m}}^{z}$, using the share of manual users $\left(S_{\mathrm{m}}\right)$ as a surrogate. The results of using different power terms $(z)$ are displayed in Fig. 5.

For a number of years the power term results behave in an orderly way. Up to year 12 , the rankings in terms of market share are clearly proportional to the power term, with higher positive power terms resulting in the highest share and lower negative power terms resulting in the lowest share. A high power term means that positive feedback for ETC is strong (a virtuous circle), users beget more users, and the magnitude of ETC-specific constant (which is negative) approaches zero quickly. A power term of 0 implies that there are no feedback effects. A negative power term implies that the more existing ETC users there are, the less likely new users will choose ETC.

However, the lower the power term (below 1), the sooner the agency will deploy all 11 lanes. That is, when it must fight against a vicious circle to maximize welfare it must make the choice of manual lanes less desirable due to high travel times. Also, the lower the power term, the lower the final ETC market share.

The best available data for the Carquinez Bridge were used to estimate the real value of the power term. The number of transponders at the Carquinez Bridge in year 2 is converted to get the approximate all-day market share, $9.2 \%$ for the second year. (The baseline model had predicted a peak-period share of $11.54 \%$, as shown in Table 2.) Assuming $6 \%$ market share for the first year, 


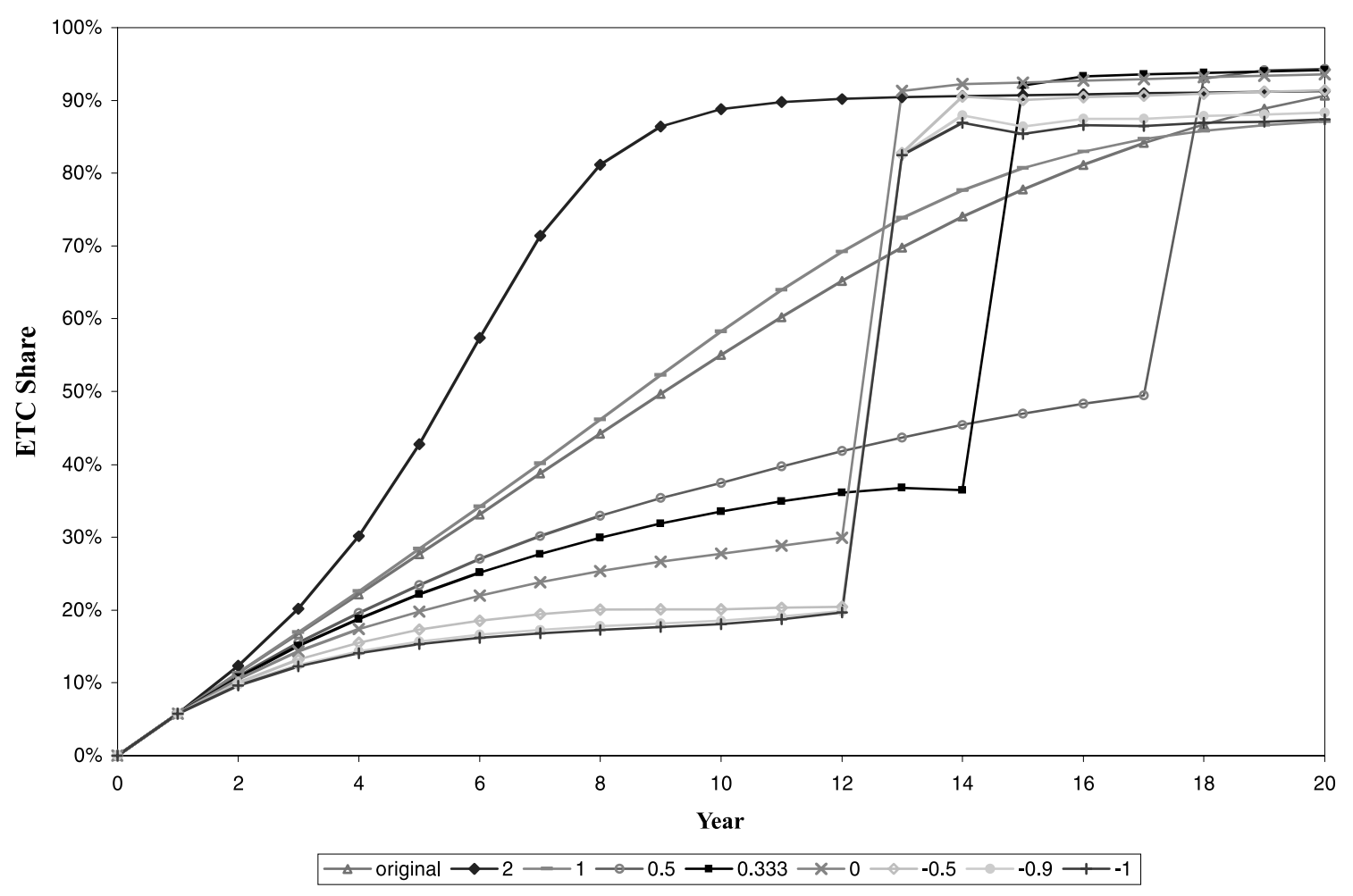

Fig. 5. Evolution of ETC market share under different power terms.

$84 \%$ survival rate, a $34.6 \mathrm{~s}$ difference in travel time, and $\$ 0.15$ discount for ETC users, the power term equals -1.636 , and the overall NPV for this scenario (as for any scenario with a negative power term) is negative.

Two points should be noted about this unpleasant result. First, this paper models the peak period, when more ETC travelers use the system, and then extrapolates that ETC value to the non-peak to determine net benefit. The data are not broken down by peak/non-peak. The market share should be higher during the peak period and the ETC-specific constant should be lower than estimated. Second, the reluctance may be that strong. That means, the toll agency has to do something to affect people's preferences if it wants to proceed with ETC. Because the Carquinez ETC system was initially considered a technology test rather than a market demonstration, very little effort had been made to sell ETC to potential customers. The initial technological difficulties and bad press associated with this particular experiment may contribute to the low ETC share at the Carquinez Bridge (Nolte, 1996). This may change significantly as ETC is deployed at other San Francisco area toll bridges.

\section{Alternative capacity rules}

In the original model, the number of ETC (and non-ETC) lanes is decided by optimizing overall NPV in a given year, independent of its consequences for future years. As discussed in the last two 
sections, a greater number of ETC lanes is estimated to result in higher overall NPV over the entire period. Is it possible to trade a suboptimal NPV in the present year for a higher long-term NPV? The original capacity rule may be dubbed "myopic optimization." Clearly, the best solution to this problem would be to optimize the ETC allocation and price discount for all 20 years simultaneously. Due to constraints on computation time, several heuristic alternatives were examined. The first heuristic, specifies higher numbers of ETC lanes in the first year, and then estimates the number of ETC lanes myopically. The second adapts the original capacity rule by adding one and two more lanes to the myopic optimization results. In the third heuristic, referred to as "bundling", instead of the idealized 20 years, the number of ETC lanes and price discount for two-, three-, and four-years are optimized simultaneously.

If travelers are forced to switch to ETC payment as early as possible, overall social welfare over the 20 years may be greater. By forcing travelers to switch earlier, future benefits may be realized earlier, at the expense of lower welfare in the first year. In this simulation, the number of ETC lanes in the first year is fixed, and the same myopic rule is applied afterwards. The evolution of ETC share with alternative capacity rules is shown in Fig. 6. Restricted by the condition that the NPV of the toll agency must exceed zero, the maximum number of ETC lanes that can be deployed in the year 1 is three. Interestingly, the saturated ETC market share converges to a certain range in year 20 no matter the initial seed number of lanes. The maximum overall is attained when two ETC lanes are installed in the first year.

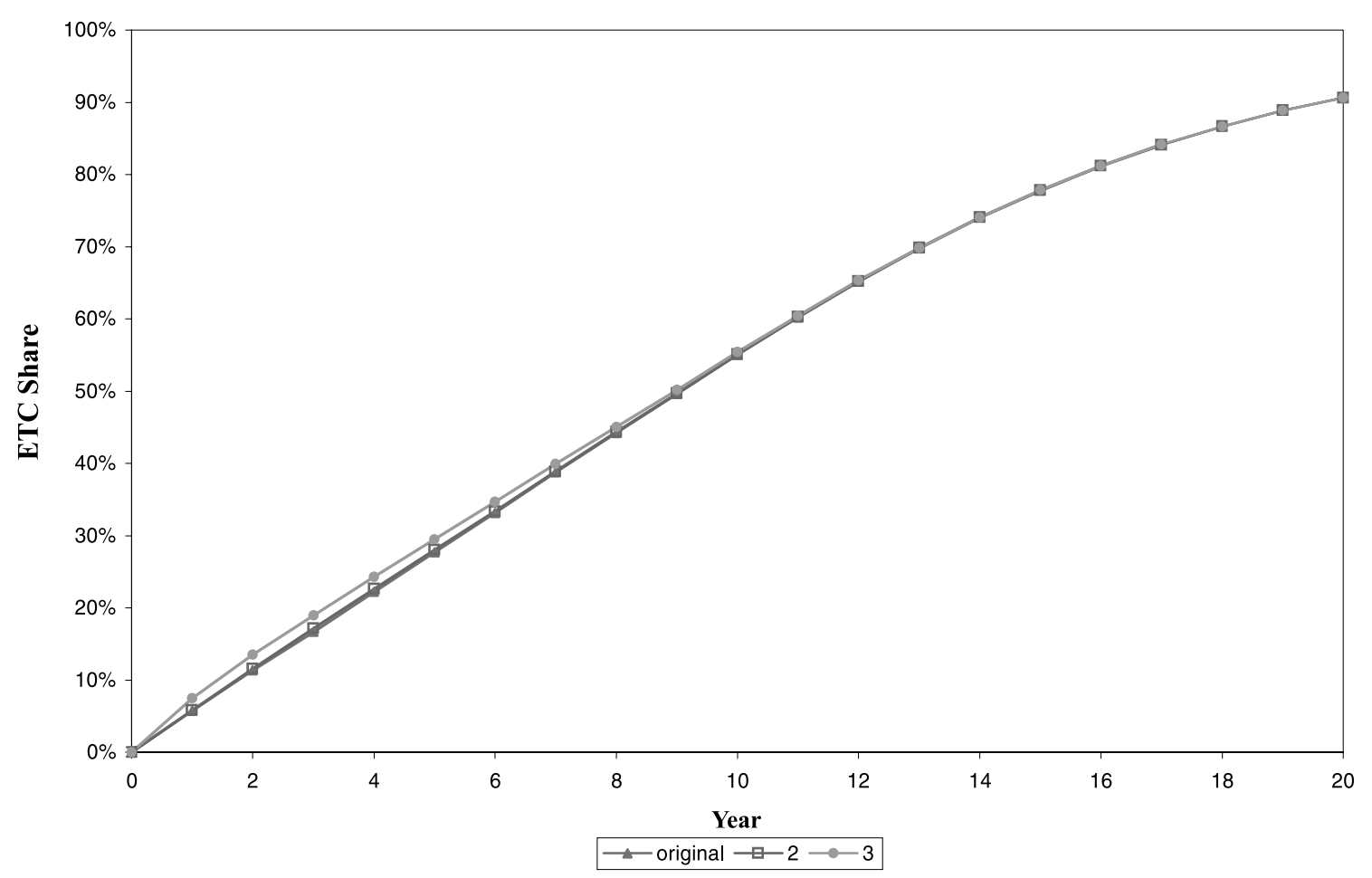

Fig. 6. Evolution of ETC share under alternative capacity rule: number of ETC lanes in the first year. 


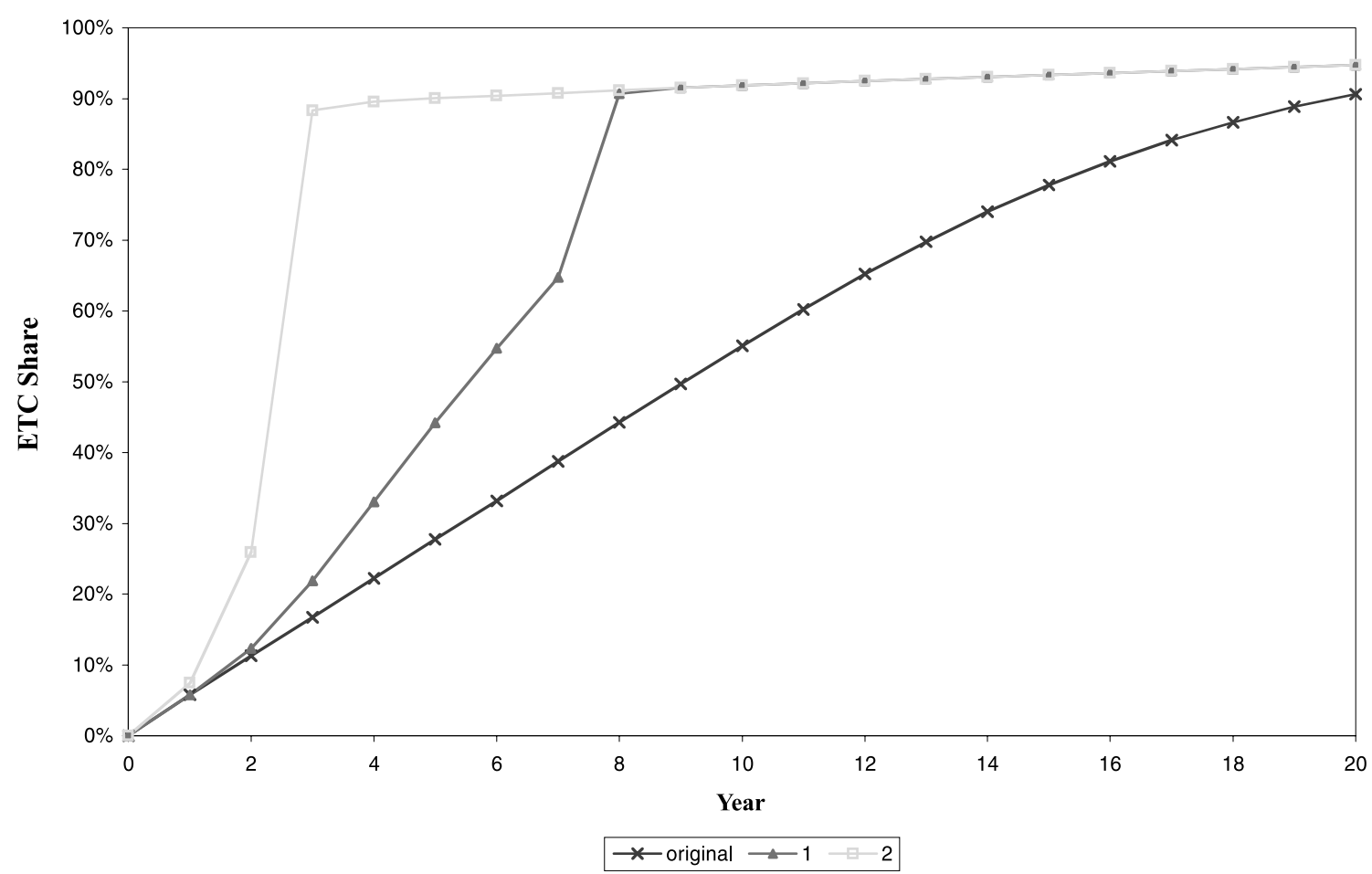

Fig. 7. Evolution of ETC share for different capacity rules.

The second rule adds one and two lanes to the number of ETC lanes computed from the myopic optimization rules. The results for evolution of ETC share with different capacity rules are shown on Fig. 7. Again, the results confirm the early observation that the earlier additional ETC lanes are deployed, the greater the overall NPV is gained over the 20-year period.

Finally, the number of ETC lanes was optimized in two-, three-, and four-year bundles, where all other assumptions are the same as in the original model. Fig. 8 depicts the results. The longer time span taken into account, the higher overall welfare attained compared to the myopic optimization rules. The welfare from a four-year optimization is superior to the two-year optimization. The three-year bundle model seems almost identical to the two-year bundle model. The gaps between two-, three-, and four-year model are not as much as between the myopic and two-year model. It is likely that the improvements one can obtain by optimization over longer time spans is limited, and faces diminishing marginal returns.

\section{Conclusions}

The conversion of conventional toll plazas to ETC is seemingly inevitable. How quickly it occurs remains to be seen. This paper examined a process that may explain the speed of this conversion if public toll agencies strive to improve the welfare for all year by year. It is clear that toll agency policy_by opening ETC lanes sooner or later-can drive user adoption of ETC. 


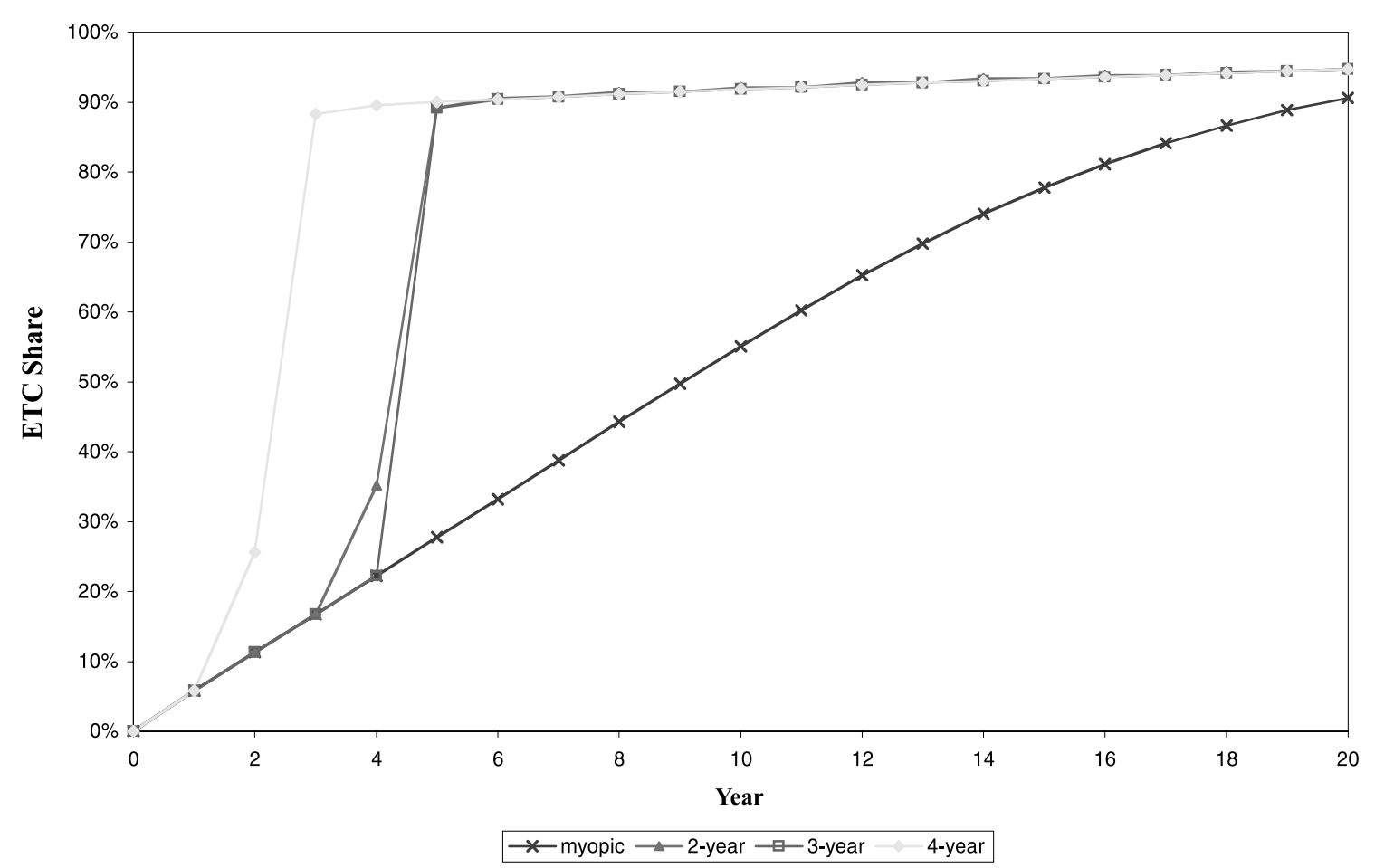

Fig. 8. Evolution of ETC share under different optimization rules.

Overall welfare is expected to improve the greater the ETC market share, and the sooner that share is achieved. Longer-term decision-making, as expected, will result in higher overall welfare than myopic decisions, though the penalty for myopia (as high as 50\%) depends on other assumptions. Many of the gains can be achieved by simply looking two years ahead; there appear to be diminishing returns to optimizing with an increasing number of years, while modeling costs rise.

This paper modeled a particular case. As a matter of course, it has raised some questions that cannot be answered, but which are critical for strategic deployment of network technologies such as ETC. In particular, there is the question of whether individuals face positive network externalities associated with a technology or whether their reluctance to make the leap is wider. While the second year of data for the Carquinez Bridge suggest the latter, that data is associated with little marketing as the agency attempts to ensure the technology is working smoothly. A more concerted marketing strategy to reduce the barriers to entry could easily shift preferences. Furthermore, deployment of ETC on other Bay Area bridges should also create a positive externality. Alternatively, use of automatic vehicle identification, such as used on Highway 407 in Toronto, which eliminates the transponder buy in, may be an alternative. Clearly, more empirical research is needed on user preferences for this and other new technologies, to ascertain which deployment scenario is most reasonable.

The single most important factor in the model that dictates if ETC fails or flourishes is whether the barrier to entry rises or falls over time. If additional users, or other factors, diminish the 
barrier, the system will take off. If they do not, those predisposed against ETC will adopt it at a smaller and smaller rate each successive year.

\section{Appendix A. Benefits and costs of ETC}

To estimate the costs and benefits, a number of basic assumptions are made. These include overall traffic growth, toll transaction time by type of payment, travel speed, design configuration of Carquinez Bridge, annual inflation rate and interest rate. The main assumptions are listed in Table 3 and explained below.

This framework identifies benefit and cost categories for travelers (time, vehicle operating costs), agencies (fixed and operating costs of toll collection, revenue), and the community (pollution). While the measure of overall NPV ignores transfers, they are considered for the NPV of each user class. Transfers include tolls paid (a transfer from the user to the toll agency), or interest on prepaid ETC credit accounts (lost to travelers but accrued to the agency). Inflation of 3\% per year is assumed for all costs and money values, before discounting back to the present with an interest rate of $6 \%$ and discount rate of $3 \%$.

Costs and benefits for each class (travelers, the toll agency, and the community) can be estimated separately. The overall social welfare $(W)$ is defined as:

$$
W=B_{\mathrm{T}}-C_{\mathrm{T}}+B_{\mathrm{A}}-C_{\mathrm{A}}+B_{\mathrm{C}}-C_{\mathrm{C}}
$$

where $B_{\mathrm{A}}, B_{\mathrm{C}}, B_{\mathrm{T}}$ are benefits for the toll agency, the community, and travelers; $C_{\mathrm{A}}, C_{\mathrm{C}}, C_{\mathrm{T}}$ are costs for the toll agency, the community, and travelers.

\section{A.1. Travelers}

Travelers are divided into two classes, referred to as manual and electronic. Cost savings for electronic travelers come from reduced delay because of higher throughputs on ETC lanes, and elimination of acceleration and deceleration processes associated with manual toll collections. For the convenience of analysis, it is assumed that the value of time, the mode split (car, truck, bus), and the average vehicle occupancy do not vary over the analysis period.

\section{A.2. Delay}

In general, delay can be decomposed into three categories: random (or overflow) delay, stop delay, and delay due to acceleration/deceleration. The random delay stands for the stochastic nature of arrivals. When the number of arriving vehicles exceeds service capacity temporarily during some period, they must wait to pay the toll. The generalized delay model suggested by Fambro and Rouphail (1997) for the new Highway Capacity Manual (TRB, 2000) is employed to estimate delay. The model is solved separately for manual and electronic lanes. The delay is only computed for peak hours, no delay is assumed outside of the peak period.

$$
D_{\mathrm{R}}=900 T_{\text {peak }}\left[(\rho-1)+\sqrt{(\rho-1)^{2}+\frac{8 \rho}{\operatorname{Tm} \mu}}\right]
$$


Table 3

Assumptions

\begin{tabular}{|c|c|c|c|}
\hline \multirow{2}{*}{$\begin{array}{l}\text { Items } \\
\text { General assumptions }\end{array}$} & \multicolumn{3}{|l|}{ Value } \\
\hline & & & \\
\hline Annual traffic growth rate & \multicolumn{3}{|l|}{$3 \%$} \\
\hline Seconds/cash transaction & \multicolumn{3}{|l|}{7.5} \\
\hline Seconds/ticket transaction & \multicolumn{3}{|l|}{4.5} \\
\hline Seconds/ETC transaction & \multicolumn{3}{|l|}{2.4} \\
\hline Normal travel speed (mph) & \multicolumn{3}{|l|}{55} \\
\hline Ramp distance to toll plaza (mile) & \multicolumn{3}{|l|}{0.2} \\
\hline Annual discount rate & \multicolumn{3}{|l|}{$6 \%$} \\
\hline Annual inflation rate & \multicolumn{3}{|l|}{$3 \%$} \\
\hline Average miles/gal & \multicolumn{3}{|l|}{25} \\
\hline Pre-tax fuel price (excluding taxes) (\$/gal) & \multicolumn{3}{|l|}{$\$ 0.74$} \\
\hline \multicolumn{4}{|l|}{ Modal use assumptions } \\
\hline & Auto & Truck & Bus \\
\hline Mode split & $94.76 \%$ & $5.11 \%$ & $0.13 \%$ \\
\hline Average vehicle occupancy & 1.258 & 1.1 & 20 \\
\hline Value of time per passenger & $\$ 12.75$ & $\$ 33.41$ & $\$ 12.75$ \\
\hline \multicolumn{4}{|l|}{ Agency assumptions } \\
\hline Costs per personal year $(\$ / P Y)$ & \multicolumn{3}{|l|}{$\$ 65,000$} \\
\hline Unit cost of ETC lanes & \multicolumn{3}{|l|}{$\$ 62,361$} \\
\hline Unit cost of transponders & \multicolumn{3}{|l|}{$\$ 28.85$} \\
\hline Person years needed for information technology & \multicolumn{3}{|l|}{0.11} \\
\hline Person years needed for accounting & \multicolumn{3}{|l|}{0.46} \\
\hline Average number of transponders per ETC account & \multicolumn{3}{|l|}{1.35} \\
\hline Average annual times an account is used & \multicolumn{3}{|l|}{160} \\
\hline \multicolumn{4}{|l|}{ Community assumptions } \\
\hline & $\mathrm{NO}_{\mathrm{x}}$ & $\mathrm{HC}$ & $\mathrm{CO}$ \\
\hline Emission rate during the acceleration (g/gal) & 24.7 & 9.5 & 209.0 \\
\hline Emission rate during the idling $(\mathrm{g} / \mathrm{min})$ & 0 & 0.15 & 2.5 \\
\hline Cost of air pollution ( $\$ / \mathrm{kg}$ of pollutant) & $\$ 1.275$ & $\$ 1.275$ & $\$ 0.0063$ \\
\hline \multicolumn{4}{|l|}{ Payment split assumptions } \\
\hline Payment split & Cash & $\begin{array}{l}\text { Ticket (credit } \\
\text { card) }\end{array}$ & \\
\hline Baseline & $\begin{array}{l}83 \% \text { in base year; } \\
83 \% \text { in year } 20\end{array}$ & $\begin{array}{l}17 \% \text { in base year; } \\
17 \% \text { in year } 20\end{array}$ & \\
\hline ETC alternative-manual users & $\begin{array}{l}83 \% \text { in base year; } \\
100 \% \text { in year } 20\end{array}$ & $\begin{array}{l}17 \% \text { in base year; } \\
0 \% \text { in year } 20\end{array}$ & \\
\hline ETC alternative-ETC users & $\begin{array}{l}64 \% \text { in base year; } \\
64 \% \text { in year } 20\end{array}$ & $\begin{array}{l}(36 \% \text { in base year; } \\
36 \% \text { in year } 20)\end{array}$ & \\
\hline
\end{tabular}

Source: Caltrans (1995a); Gillen et al. (1999) pp. 13, 21, 22, A-13, Table B-1,B-2, C-2; Small and Kazimi (1995); ETTM on the web, US DOT/FHWA, Highway Statistics (1996); Cicero-Fernandez and Long (1993).

where $D_{\mathrm{R}}$ is average random delay (s); $T_{\text {peak }}$ is duration of peak period (h); $\mu$ is capacity of one lane (vehicle/h); $m$ is number of lanes; $\lambda$ is total arrival rate during the peak period (vehicle/h); $\rho$ is degree of saturation, $\rho=\lambda / m \mu$. 
The stop delay is the time required by a manual user to pay the toll. For manual lanes, mean transaction time is the weighted transaction time by payment type split. The service capacity is then the inverse of the mean transaction time. Service times are assumed uniform. For ETC lanes, transaction time is assumed to be $0 \mathrm{~s}$, and the capacity is determined by the minimum headway, $2.4 \mathrm{~s}$ (1500 vehicle/h) in the Carquinez Bridge case (which retrofits ETC lanes to an older toll plaza design).

In order to make a complete stop at the toll plaza, a manual user has acceleration/deceleration delay. The distance traveled during this process is the length of ramps from and leading to the toll plaza. Drivers are assumed to accelerate and decelerate at a constant rate, and thus the average travel speed is equal to one half of the normal or desired travel speed. The acceleration delay is estimated by dividing the length of the ramp leading to the toll plaza by this average travel speed. The same estimate is applied to the deceleration process. Electronic users escape both stop delay and acceleration-deceleration delay (if the toll plaza's ETC lanes are full speed and properly separated).

\section{A.3. Vehicle operating costs}

ETC users also benefit from the reduction in vehicle operating costs, mainly in fuel consumption. In general, engines need more fuel during acceleration than other times. Thus, only fuel consumption during acceleration is considered. Fuel costs are estimated as follows:

$$
C_{\mathrm{GT}, n}=T_{\text {plaza }, n} G_{\mathrm{a}} C_{\mathrm{G}}\left(1+I_{\mathrm{f}}\right)^{n}
$$

where $C_{\mathrm{GT}, n}$ is total gasoline costs in year $n(\$) ; G_{\mathrm{a}}$ is gasoline consumption during acceleration $(\mathrm{gal} / \mathrm{h}) ; I_{\mathrm{f}}$ is annual inflation rate; $T_{\text {plaza }, n}$ is time needed to travel the length of toll plaza ramps in year $n,(\mathrm{~h} / \mathrm{yr}) ; C_{\mathrm{G}}$ is cost of gasoline in base year (excluding taxes) (\$/gal).

\section{A.4. Demand}

Traffic forecasts are exogenous to the model. Here, following Gillen et al. (1999), forecast demand is expected to rise from $19,016,000$ to $30,000,000$ vehicle/yr at a uniform increment $(\sim 2.9 \% / \mathrm{yr}$ in the first year to $1.8 \% / \mathrm{yr}$ in the final year), based on historic trends. To estimate the future peak hour volume, the base-year ratio of average annual daily traffic (AADT) to peak hour volume (PHV) through the toll plaza is computed and assumed to stay constant over time. During the evening peak hour, this ratio is 0.0995 , and during the morning peak hour it is 0.0277 for the Carquinez Bridge. (The tollbooth is located on eastbound I-80, which is outbound from San Francisco and Oakland.) If the peak spreads, this assumption probably overestimates the peak hour ratio.

\section{A.5. Agency}

The agency has both one-time and continuing operating costs. One-time costs are expended to establish new systems, while operating costs are incurred daily to operate the system. Among the one-time costs, some are spent at the beginning of the project and are independent of the number 
of open lanes and traffic level. The costs of installing additional ETC lanes and purchasing transponders are allocated to the year associated with the incremental increase in ETC users.

The operating costs can be divided into three categories: staffing, hardware/software, and other. Staffing is comprised of employees in information technology, accounting, and toll collection. Personnel costs for information technology $\left(Y_{\mathrm{I}}\right)$ and accounting $\left(Y_{\mathrm{A}}\right)$ are assumed constant over time (Caltrans, 1995a,b). Only toll collection personnel $\left(Y_{\mathrm{T}_{n}}\right)$ vary with manual traffic volume, so those are estimated by the model. A promising cost savings for the toll agency from adopting the ETC alternative is the reduction in toll collection staff, proportionate to the number of manual lanes. Staff costs are estimated by multiplying the personnel needed for each alternative and the cost per person. The number of persons needed for toll collection can be estimated given forecast annual traffic volume and ETC market share. The costs of staffing can be obtained as follows.

$$
C_{\mathrm{PT}, n}=C_{\mathrm{P}}\left(Y_{\mathrm{A}}+Y_{\mathrm{I}}+Y_{\mathrm{T}_{n}}\right)\left(1+I_{\mathrm{f}}\right)^{n}
$$

where $C_{\mathrm{PT}, n}$ is total personnel cost in year $n(\$) ; C_{\mathrm{P}}$ is person year costs in base year $(\$ / \mathrm{yr}) ; Y_{\mathrm{A}}, Y_{\mathrm{I}}$, $Y_{\mathrm{T}_{n}}$ are person years for accounting, information, toll collection in year $n$.

The toll collection staff is balanced with the traffic level in the base year. Furthermore, all manual lanes are assumed to be open during the peak hour, and the personnel needed during the off-peak period is proportional to the number of manual transactions during the off peak. Offpeak traffic is estimated by subtracting projected annual peak traffic from the projected annual traffic volume. In this model the ETC share is the same during the peak and off-peak period. However, it might be more realistic to expect that the ETC share will be higher during the peak hours when significant time may be saved, and because peak travelers are more regular users of the system. Hardware/software costs for information technology and other program costs are estimated from the ATCAS Report (Caltrans, 1995a,b).

\section{A.6. Community}

The primary benefit of ETC systems to communities at large is the reduction of $\mathrm{NO}_{\mathrm{x}}, \mathrm{HC}$, and $\mathrm{CO}$ emission during idling and acceleration. The magnitude of the emissions impacts are small however, compared with the other impact dimensions. Emission rates are given in Table 3. Total emissions of pollutant $p$ from idling in year $n\left(E_{\mathrm{idleT}, p, n}\right)$, (in $\left.\mathrm{gm}\right)$ are estimated as follows.

$$
E_{\text {idleT }, p, n}=T_{\text {idle, } \mathrm{n}} E_{\text {idle, } p} 60
$$

where $T_{\mathrm{idle}, n}$ is time idling in year $n(\mathrm{~h}) ; E_{\mathrm{idle}, p}$ is emission rate for pollutant type $p$ during idling (gm/ $\min )$.

Total emissions of pollutant $p$ from acceleration in year $n\left(E_{\text {accT,p,n }}\right)$ (in gm) are:

$$
E_{\mathrm{accT}, p, n}=\left(T_{\mathrm{plaza}, n}\right) G_{\mathrm{a}} E_{\mathrm{acc}, p}
$$

where $E_{\text {acc }, p}$ is emission rate of pollutant type $p$ during acceleration (gm/gal); $G_{\mathrm{a}}$ is fuel consumption rate during acceleration (gal/h). 


\section{References}

Al-Deek, H.M., Radwan, A.E., Mohammed, A.A., Klodzinski, J.G., 1996. Evaluating the improvements in traffic operations at a real-life toll plaza with electronic toll collection. ITS Journal 3 (3), 205-223.

Al-Deek, H.M., Mohamed, A.A., Radwan, A.E., 1997. Operational benefits of electronic toll collection: case study. Journal Of Transportation Engineering V123 (N6).

Asahi Shimbun, 2001. Ministry to slash electronic toll fees, August 1, 2001, appearing in English Language supplement of Asahi Shimbun to International Herald Tribune.

Ben-Akiva, M., Lerman, S., 1985. Discrete Choice Analysis. MIT Press, Cambridge MA.

Burris, M., Hildebrand, E., 1996. Using microsimulation to quantify the impact of electronic toll collection. ITE Journal V66 (N7), 21-24.

California Department of Transportation (Caltrans), 1995a. Advanced Toll Collection and Accounting System (ATCAS) Feasibility Study Report. TIRU Project \#2400-146.

California Department of Transportation (Caltrans), 1995b. Annual Financial Report: State Owned Toll Bridges.

Chang, E.C.-H., David, L., David, G. 1998. User's Manual For Computerized Benefit-Cost Analysis Of Electronic Toll Collection System (October 28, 1998), Filed as part of MOU-357.

Cicero-Fernandez, P., Long, J., 1993. Modal Acceleration Testing on Current Technology Vehicles. California Air Research Board, El Monte California.

ETTM, 2001. Table: United States ETC Systems In Production/Development. Available from $<$ http://www.ettm.com/ $>$.

Fambro, D.B., Rouphail, N.M., 1997. Generalized delay model for signalized intersections and arterial streets. Transportation Research Record 1572.

Federal Highway Administration, US DOT. 1996. Highway Economic Requirements System, vol. IV: Technical Report. DOT-VNTSC-FHWA-96-6, p. 8-28.

Fimrite, P., 2001. FasTrak Putting The Brakes On Golden Gate Bridge Discounts, Originally posted in: The San Francisco Chronicle, June 29, 2001.

Friedman, D.A., Waldfogel, J., 1995. The administrative and compliance cost of manual highway toll collection: evidence from Massachusetts and New Jersey. National Tax Journal V48 (N2), 217-228.

Gillen, D.L.J., Dahlgren, J., Chang, E., 1999. Assessing the Benefits and Costs of ITS Projects: vol. 2, An Application to Electronic Toll Collection. California PATH Research Report UCB-ITS-PRR-99-10.

Hensher, D., 1991. Electronic Toll Collection Transportation Research Part A-General 25 (1), 9-16.

Levinson, D.M., 1997. Job and housing tenure and the journey to work. Annals of Regional Science 31 (4), 451471.

Lin, F.-B., Su, C.-W., 1994. Level-of-service analysis of toll plazas on freeway main lines. Journal of Transportation Engineering 120 (2), 246-263.

Miller E.J., 1996. Microsimulation and activity-based forecasting. In: Activity-Based Travel Forecasting Conference Proceedings June 2-5, 1996. Summary, Recommendations and Compendium of Papers, February, 1997. Available from $<$ http://www.bts.gov/tmip/papers/tmip/abtf/miller.htm $>$.

Nolte, C., 1996. Automatic Tollbooth Technology Not Yet Ready for Prime Time, San Francisco Chronicle, September 23, 1996.

Ortuzar, Juan de Dios, Willumsen, Luis, 1996. Modelling Transport. John Wiley \& Sons.

Purvis, C.L., 1996. Use of census data in transportation planning: San Francisco Bay area case study, Decennial census data for transportation planning. In: Case Studies and Strategies for 2000 Conference Proceedings 13, vol. 2. National Academy Press, Washington, DC, 1997, pp. 58-67. Available from <http://www.mtc.ca.gov/datamart/ census/irvine96.htm >.

Robinson, M., Van Aerde, M., 1995. Examining the delay and environmental impacts of toll plaza. In: 1995 Vehicle Navigation \& Information Systems Conference Proceedings - 6th International VNIS, July 30-August 2, 1995, Washington State Convention and Trade Center, Seattle, Washington, USA.

Sisson, M., 1995. Air quality benefits of electronic toll collection. Transportation Quarterly 49 (4), 93.

Small, K.A., Kazimi, C., 1995. On the costs of air pollution from motor vehicles. Journal of Transport Economics and Policy, 7-32.

Train, K., 1986. Qualitative Choice Analysis. MIT Press, Cambridge MA. 
Transportation Research Board (TRB), 2000. Highway Capacity Manual, Special Report 209. Transportation Research Board, Washington, DC.

Woo, T.H., Hoel, L.A., 1991. An Investigation of Toll Plaza Capacity and Level of Service. Virginia Transportation Research Council.

Zarrillo, M., Radwan, A., Al-Deek, H., 1997. Modeling traffic operations at electronic toll collection and traffic management systems. Computers and Industrial Engineering 33 (3-4), 857-860. 